\section{(6) OPEN ACCESS}

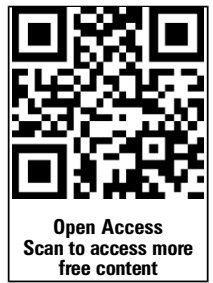

- Additional material is published online only. To view please visit the journal online (http://dx.doi.org/10.1136/ heartjnl-2015-308237)

${ }^{1}$ Département de Cardiologie, Hôpital Européen Georges

Pompidou, Paris, France ${ }^{2}$ INSERM U970, Paris Cardiovascular Research Centre PARCC, Paris, France ${ }^{3}$ Université Paris Descartes, Sorbonne Paris Cité, Paris, France

${ }^{4}$ Department of Cardiology, Centre Hospitalier Territorial de Nouvelle Calédonie, Nouméa, New Caledonia

${ }^{5}$ University of Oxford, Oxford, UK

${ }^{6}$ Agence Sanitaire et Sociale de Nouvelle Calédonie, Nouméa, New Caledonia

${ }^{7}$ Direction des Affaires Sanitaires et Sociales, Nouméa New Caledonia

${ }^{8}$ Département des Evacuations Sanitaires, Contrôle Médical Unifié, CAFAT, Nouméa, New Caledonia

\section{Correspondence to} Dr Mariana Mirabel, Paris Cardiovascular Research Centre, Inserm U970, Hôpital Européen Georges Pompidou, 56 rue Leblanc, 75737 Paris, CEDEX 15, France; mariana.mirabel@inserm.fr

Received 3 June 2015 Revised 1 October 2015 Accepted 2 October 2015

\section{CrossMark}

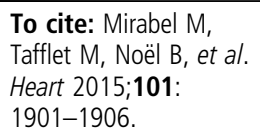

\title{
Newly diagnosed rheumatic heart disease among indigenous populations in the Pacific
}

\author{
Mariana Mirabel, ${ }^{1}, 2,3$ Muriel Tafflet, ${ }^{2,3}$ Baptiste Noël, ${ }^{4}$ Tom Parks, ${ }^{5}$ Olivier Axler, ${ }^{4}$ \\ Jacques Robert, ${ }_{1}^{4}$ Marie Nadra, ${ }^{4}$ Gwendolyne Phelippeau, ${ }_{1}{ }^{4}$ Elodie Descloux ${ }_{1}{ }^{4}$ \\ Cécile Cazorla, ${ }_{1}^{4}$ Isabelle Missotte, ${ }^{4}$ Shirley Gervolino, ${ }^{4}$ Yann Barguil, ${ }^{4}$ \\ Bernard Rouchon, ${ }^{6}$ Sylvie Laumond ${ }_{1}^{7}$ Thierry Jubeau ${ }^{8}$ Corinne Braunstein, ${ }^{4}$ \\ Jean-Philippe Empana, ${ }_{1}^{2,3}$ Eloi Marijon, ${ }^{1,2,3}$ Xavier Jouven ${ }^{1,2,3}$
}

\begin{abstract}
Objectives Rheumatic heart disease (RHD) remains the leading acquired heart disease in the young worldwide.

We aimed at assessing outcomes and influencing factors in the contemporary era.

Methods Hospital-based cohort in a high-income island nation where RHD remains endemic and the population is captive. All patients admitted with newly diagnosed RHD according to World Heart Federation echocardiographic criteria were enrolled (2005-2013). The incidence of major cardiovascular events (MACEs) including heart failure, peripheral embolism, stroke, heart valve intervention and cardiovascular death was calculated, and their determinants identified.
\end{abstract}

Results Of the 396 patients, $43.9 \%$ were male with median age 18 years (IQR 10-40)). $127(32.1 \%)$ patients presented with mild, 131 (33.1\%) with moderate and $138(34.8 \%)$ with severe heart valve disease. $205(51.8 \%)$ had features of acute rheumatic fever. $106(26.8 \%)$ presented with at least one MACE. Among the remaining 290 patients, after a median follow-up period of 4.08 (95\% Cl 1.84 to 6.84 ) years, 7 patients (2.4\%) died and $62(21.4 \%)$ had a first MACE. The annual incidence of first MACE and of heart failure were $59.05 \%$ (95\% Cl 44.35 to 73.75$)$ and $29.06 \%$ (95\% Cl 19.29 to 38.82$)$, respectively. The severity of RHD at diagnosis (moderate vs mild HR 3.39 (0.95 to 12.12); severe vs mild RHD HR 10.81 (3.11 to $37.62), p<0.001)$ and ongoing secondary prophylaxis at follow-up (HR $0.27(0.12$ to 0.63 ), $p=0.01$ ) were the two most influential factors associated with MACE. Conclusions Newly diagnosed RHD is associated with poor outcomes, mainly in patients with moderate or severe valve disease and no secondary prophylaxis.

\section{INTRODUCTION}

Rheumatic heart disease (RHD), a disease of poverty, ${ }^{1}$ has almost disappeared from wealthy countries, but remains highly prevalent in developing countries and among indigenous populations in the Pacific. ${ }^{2-7}$ The burden of RHD is still a major challenge in the developing world with approximately 345000 deaths per year worldwide. ${ }^{8}$ RHD is the result of an inadequate response to invasive group A streptococcal infections, namely acute rheumatic fever (ARF). ${ }^{9}$ Although they are part of a continuum, RHD and ARF have often been studied separately. The presentations do vary, however, with some patients presenting with ARF and no overt cardiac involvement, and nearly half of those diagnosed with RHD at an advance stage having no history of ARF. ${ }^{10} 11$

There is, however, limited contemporary data on the characteristics of patients with newly diagnosed RHD. ${ }^{10}$ Also, a handful of clinical studies assessing predictors of outcomes in ARF and RHD either present a highly selected population ${ }^{12}$ or date back to the 1950 s when access to interventions was extremely limited. ${ }^{13}$ The two contemporary hospital-based registers have so far described characteristics of patients with no or limited (up to 30 months) follow-up. ${ }^{10} 11$

We present the results of a hospital-based cohort study in New Caledonia, a high-income country where RHD remains endemic among the indigenous population. ${ }^{6}$ The objective was twofold: to describe the characteristics and outcomes of patients with newly diagnosed RHD according to standardised and prespecified diagnostic criteria and to assess factors associated with outcomes, focusing on patients with no major cardiovascular events (MACEs) at entry.

\section{METHODS}

\section{Settings}

RHD remains prevalent in New Caledonia among Oceanic populations including Melanesians and Polynesians. ${ }^{6}$ New Caledonia (22.276 S, 166.458 E) is an overseas French territory of approximately 270000 inhabitants located in the southwest Pacific Ocean. ${ }^{14}$ The Centre Hospitalier Territorial de Nouvelle Calédonie is the only centre that provides specialist Cardiology, Paediatrics and Infectious Disease services in the archipelago and uses computer-based notes. The New Caledonian social security system provides free of charge access to good quality medicine, imaging and microbiological diagnostic testing. Air transport for urgent referral for remote communities is widely available across the archipelago. Patients in need for heart valve surgery are referred either to neighbouring Australia or to mainland France with no additional cost for the patient.

\section{Participants}

Patients admitted with newly diagnosed RHD from 1 January 2005 to 31 December 2013 were 
considered eligible for the study. Hospital records of all individuals with a primary or secondary International Classification of Diseases, 10th revision separation diagnosis of ARF or RHD were examined. Patients who fulfilled World Heart Federation (WHF) criteria of 'definite' $\mathrm{RHD}^{15}$ with quantification of heart valve disease ${ }^{16}$ were included in the study (see online supplementary table S1). Patients were asked to give oral consent to be enrolled in the study at time of follow-up interview.

\section{Data collected at the time of diagnosis}

For each participant, the following data were retrospectively collected: demographics (age, sex), ethnicity, month and year of diagnosis, family history of RHD, ARF at presentation, valve disease on first echocardiogram and its severity, ${ }^{16}$ New York Heart Association (NYHA) class, LVEF on echocardiogram, pulmonary hypertension on echocardiogram (defined as pulmonary artery systolic pressure $>35 \mathrm{~mm} \mathrm{Hg}$ ), presence of supraventricular arrhythmias (defined as paroxysmal or permanent atrial fibrillation, atrial flutter or atrial tachycardia). Mild heart valve disease included mild single left-sided valve disease and mild multiple heart valve disease (eg, mild mitral regurgitation and mild aortic regurgitation). Heart valve disease was considered moderate if one of the left-sided valves presented with moderate mitral regurgitation, mitral stenosis or aortic regurgitation. One single severe left-sided regurgitative/stenotic valve lesion was considered severe heart valve disease. ${ }^{16}$

\section{Follow-up}

Patients were invited to attend a specialist clinic from March 2013 to December 2013. If patients could not attend, a questionnaire was filled over the telephone either with the patient or the general practitioner, and the latest medical reports were collected.

Data on treatment included use of secondary prophylaxis (benzathine penicillin $\mathrm{G}$ injections or oral treatment) at any time from diagnosis and at the time of interview (ie, ongoing secondary prophylaxis). The National Register of Secondary Prophylaxis was consulted when data were missing on the hospital chart. The population being captive, all major events (see below) such as heart failure, stroke or embolism would lead to admission to the single hospital in the archipelago. Vital status and cause of death were checked in the national register of the causes of death in March 2014 for patients lost to follow-up between March and December 2013. Use of cardiac interventions through the office in charge of overseas referrals was also checked in March 2014.

\section{Outcomes and factors associated with events}

MACEs, based on information available in the hospital chart, included heart failure (defined by NYHA class III or IV), peripheral embolism, stroke, heart valve intervention and cardiovascular death. Heart valve interventions included percutaneous mitral valvuloplasty and open-heart valve surgery. Additional adverse events were collected: severe haemorrhage (defined as leading to death, intracranial bleeding, bleeding associated with haemoglobin drop of $\geq 2 \mathrm{~g} / \mathrm{dL}$ or need for transfusion of at least 2 red cell packs), infective endocarditis, heart valve thrombosis (in patients with a mechanical valve), cardiogenic shock and pregnancy-related complications (defined as maternal or foetal complications, including heart failure, need for surgery, termination of pregnancy, preterm birth and low birth weight). A team of two research nurses collected the data. A third party (MM) arbitrated in case of disagreement.

\section{Statistical methods}

Descriptive data were reported for the entire study population fulfilling the WHF criteria for RHD. Only patients with no MACE at hospital admission were further eligible for the analysis on incident MACE. The results are reported as median and IQR or as numbers and percentages. Categorical variables were compared using $\chi^{2}$ test or Fisher's exact test, and continuous variables using Student's t test. The incidence of cardiovascular
Figure 1 Flow chart of the study. ARF, acute rheumatic fever; MACE, major cardiovascular event; RHD, rheumatic heart disease; WHF, World Heart Federation.

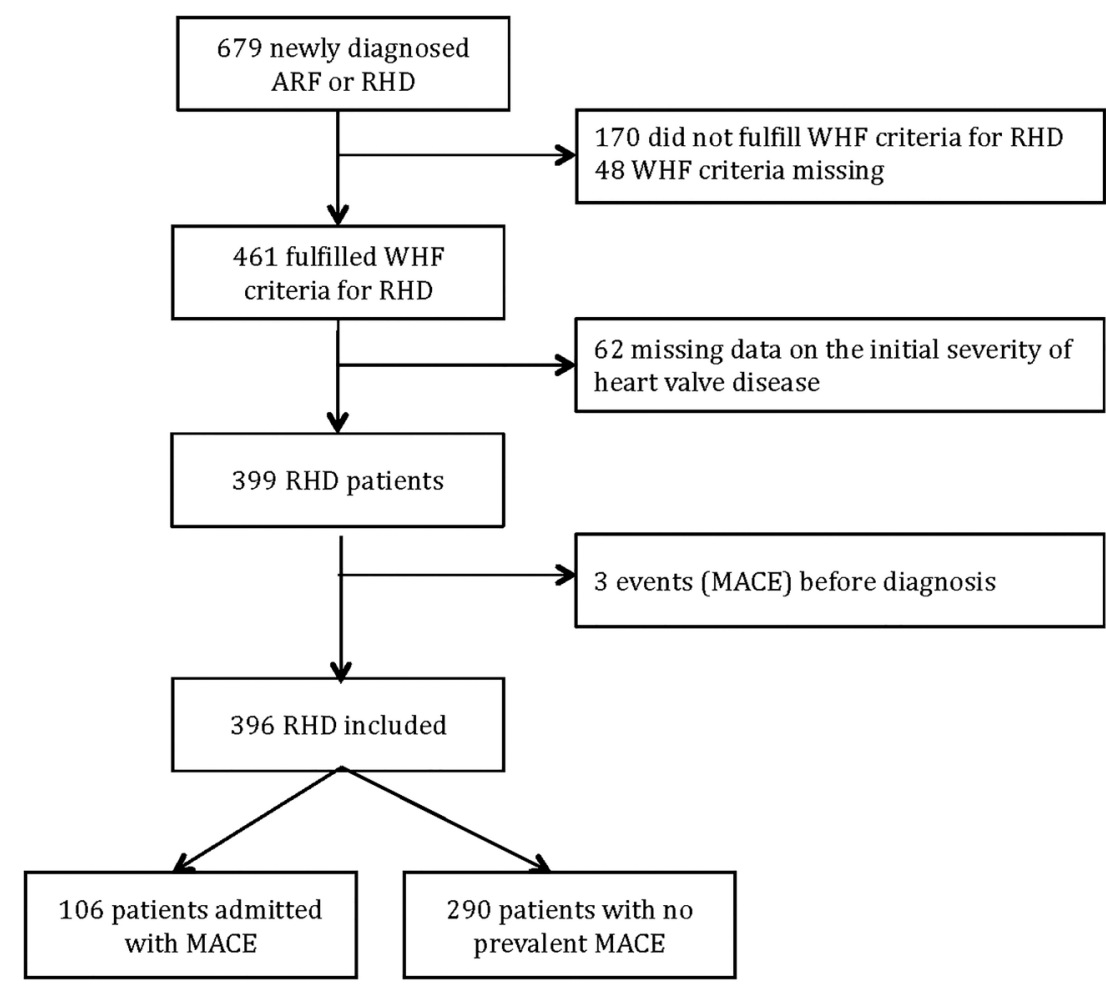


events was calculated per 1000 person-years. Factors associated with MACE were analysed using a Cox proportional hazard model. Time to event was calculated as time from diagnosis to first event or last follow-up. HRs for the Cox model were calculated accordingly with their 95\% CIs. Sensitivity analysis was performed in regards to the use and duration of secondary prophylaxis as this information was missing in a significant number of patients; we, therefore, added the variable 'ongoing secondary prophylaxis at follow-up' in the final model. Significance was defined as $\mathrm{p}$ values $<0.05$. All data were verified and analysed at the Paris Cardiovascular Research Centre, INSERM 970, Paris, France, with the use of Statistical Analysis System software (V.9.3).

\section{RESULTS}

\section{Characteristics of patients with newly diagnosed RHD}

Among the 679 patients with newly diagnosed RHD or ARF, 396 patients were included (figure 1). In total, 174 (43.9\%) were male with a median age of 18 years (IQR 10-40). And $274(71.9 \%)$ were indigenous Melanesians, 85 (22.3\%) were Polynesians and $22(5.8 \%)$ were of other ethnicity. Also, 205 (51.8\%) presented with ARF. Based on standardised echocardiograms, $127(32.1 \%)$ patients had mild heart valve disease, 131 (33.1\%) had moderate valve disease and 138 (34.8\%) had severe heart valve disease at the time of diagnosis. Mitral regurgitation was the most frequent heart valve disease, followed by aortic regurgitation and mitral stenosis (table 1). Multiple valve disease was present in $56.3 \%$ of cases. Moderate or severe tricuspid regurgitation was present in $4.5 \%$ of patients. $32(8.1 \%)$ patients had permanent or paroxysmal atrial fibrillation. Thirty-seven (9.3\%) patients had LVEF $<60 \%$. Characteristics of patients did not vary according to the year of RHD diagnosis (data not shown). Female indigenous patients were more likely to be unemployed $(p=0.026)$ and presented more often with mitral stenosis $(p=0.02)$ on univariate analysis compared with their male counterparts.

Among the 396 patients included, 106 (26.8\%) presented with MACE at entry. There were $83 / 106$ patients admitted with heart failure, among which 12 leading to urgent valve intervention (ie, within 30 days), 5 with concomitant stroke and 1 with concomitant stroke and urgent intervention. In addition, 12/106 patients were admitted with stroke; 10/106 underwent urgent intervention and 1 was admitted with stroke and underwent intervention.

Patients with no MACE at presentation were eligible for further analysis. Characteristics of these 290 patients with no MACE at entry are depicted in online supplementary table S2. Briefly, median age was 13 (IQR 10-31) years, 131 (45.2\%) were male and $185(63.8 \%)$ presented with ARF. Patients with ARF were younger $(p<0.01)$, had more often a family history of ARF $(p=0.01)$, less atrial arrhythmias $(p<0.01)$ and had different heart valve disease pattern $(p<0.01)$ compared with those with no ARF.

\section{Outcomes and their determinants in patients with no MACEs at entry}

The 290 patients were followed up for median 4.08 (95\% CI 1.84 to 6.84 ) years. Vital status and cardiac interventions data were available in all participants. Overall, there were $62 \mathrm{MACE}$; the annual incidence of MACE was 59.05\% (95\% CI 44.35 to 73.75); and median follow-up period to MACE was 10.49 (95\% CI 2.04 to 35.03 ) months. Taken individually, the annual incidence of heart failure (34 patients) was 29.06\% (95\% CI 19.29 to 38.82 ). The annual incidence of stroke was $7.26 \%$
Table 1 Characteristics at diagnosis

\begin{tabular}{|c|c|}
\hline Characteristics at diagnosis & All $\mathrm{N}=396$ \\
\hline Age, median (IQR) & $18(10-40)$ \\
\hline Male, n (\%) & $174(43.9)$ \\
\hline \multicolumn{2}{|l|}{ Ethnicity* } \\
\hline Indigenous Melanesians & $274(71.9)$ \\
\hline Polynesians & $85(22.3)$ \\
\hline Other & $22(5.8)$ \\
\hline Presentation with ARF & $205(51.8)$ \\
\hline Family history of RHD or ARF† & $114(60.6)$ \\
\hline Supra ventricular arrhythmias $\ddagger$ & $32(8.1)$ \\
\hline \multicolumn{2}{|c|}{ Initial left-sided valve disease on echocardiogram } \\
\hline \multicolumn{2}{|l|}{ Mitral regurgitation, n (\%) } \\
\hline Nil & $69(17.4)$ \\
\hline Grade $1 / 4$ & $162(40.9)$ \\
\hline Grade $2 / 4$ & $110(27.8)$ \\
\hline Grade $\geq 3 / 4$ & $55(13.9)$ \\
\hline \multicolumn{2}{|l|}{ Mitral stenosis, n (\%) } \\
\hline Nil & $265(66.9)$ \\
\hline Mild & $42(10.6)$ \\
\hline Moderate & $30(7.6)$ \\
\hline Severe & $59(14.9)$ \\
\hline \multicolumn{2}{|l|}{ Aortic regurgitation, $\mathrm{n}(\%)$} \\
\hline Nil & $201(50.8)$ \\
\hline Grade $1 / 4$ & $109(27.5)$ \\
\hline Grade $2 / 4$ & $53(13.4)$ \\
\hline Grade $\geq 3 / 4$ & 33 (8.) \\
\hline \multicolumn{2}{|l|}{ Aortic stenosis, $\mathrm{n}(\%)$} \\
\hline Nil & $370(93.4)$ \\
\hline Mild & $10(2.5)$ \\
\hline Moderate & $9(2.3)$ \\
\hline Severe & $1(0.5)$ \\
\hline Multiple left-sided valve disease, $\mathrm{n}(\%)$ & $223(56.3)$ \\
\hline \multicolumn{2}{|l|}{ Overall severity of RHD§ } \\
\hline Mild & $127(32.1)$ \\
\hline Moderate & $131(33.1)$ \\
\hline Severe & $138(34.8)$ \\
\hline Moderate or severe TRף, $\mathrm{n}(\%)$ & $17(4.5)$ \\
\hline LVEF $<60 \%, n(\%)$ & $37(9.3)$ \\
\hline PASP>35 mm Hg, n (\%) & $74(18.7)$ \\
\hline \multicolumn{2}{|c|}{$\begin{array}{l}\text { *Missing data in } 15 \text { cases. } \\
\text { tUp to second-degree relatives; missing data in } 208 \text { cases. } \\
\text { †Defined as paroxysmal or persistent atrial fibrillation, flutter or atrial tachycardia. } \\
\text { §Defined as mild RHD if single or multiple left-sided valve disease graded as mild; } \\
\text { moderate RHD defined as at least mitral or aortic moderate valve disease } \\
\text { (regurgitation or stenosis); severe RHD defined as at least mitral or aortic severe valve } \\
\text { disease (regurgitation or stenosis). } \\
\text { १Missing data in } 22 \text { cases. } \\
\text { AR, aortic regurgitation; ARF, acute rheumatic fever; PASP, pulmonary artery systolic } \\
\text { pressure; RHD, rheumatic heart disease; TR, tricuspid regurgitation. }\end{array}$} \\
\hline
\end{tabular}

(95\% CI 2.52 to 12.01) (see online supplementary table S3). The survival rate was $97.89 \%$ (CI 95\% 95.97 to 99.64) at 4 years, and $96.21 \%$ (CI $95 \% 89.95$ to 98.60 ) at 8 years after diagnosis. During the study period, seven patients $(2.4 \%)$ died, of whom four from cardiovascular death (ie, incidence of RHD-attributable mortality of $3.16 \%$ (95\% CI 0.06 to 6.26) per year). Causes of cardiovascular death included heart failure $(\mathrm{N}=2)$, stroke $(\mathrm{N}=1)$ and infective endocarditis $(\mathrm{N}=1)$. Other events were noted during the study period: atrial fibrillation in seven patients $(2.4 \%)$, infective endocarditis in eight patients $(2.8 \%)$, cardiogenic shock in two patients $(0.70 \%)$ and major haemorrhage in eight patients (2.8\%). Among the 59 women in 


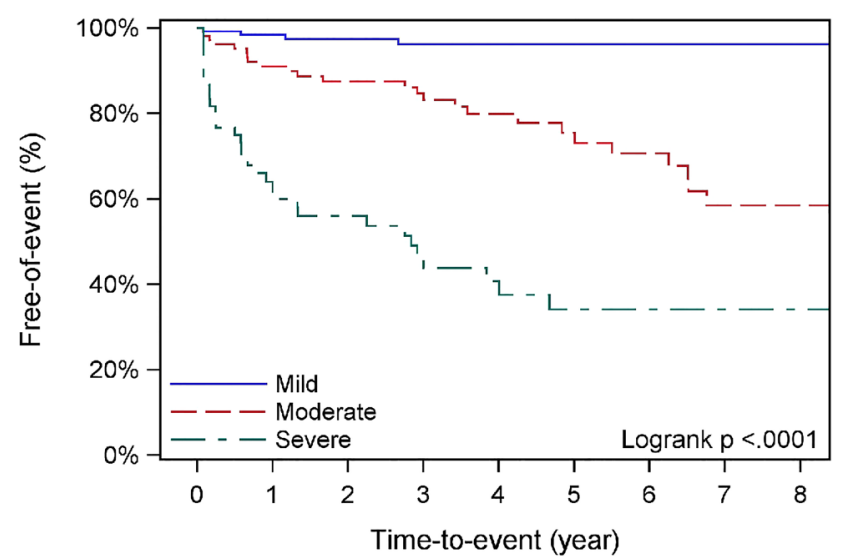

Patients at risk

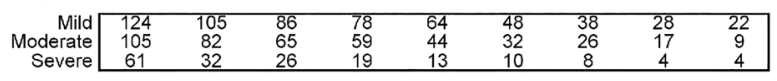

Figure 2 Kaplan-Meier survival free of major cardiovascular events (including heart valve interventions, heart failure, stroke, peripheral embolism and cardiovascular death) according to the severity of heart valve disease on echocardiogram at diagnosis.

childbearing age (ie, 15-45 years of age), 9 (15.2\%) developed complications during subsequent pregnancies.

Among the 290 patients, secondary prophylaxis was prescribed at least at one point in time in $235(83.0 \%)$ patients, no secondary prophylaxis was ever prescribed in 48 (17.0\%) patients (missing data in 7 cases). Continuation of secondary prophylaxis was reported in 159 out of $222(71.6 \%)$ patients (missing data regarding timing of prophylaxis in 61 cases). The use of secondary prophylaxis at the time of interview varied according to age $(7.5 \%$ in patients aged $>40$ years; $94.7 \%$ in patients aged 5-20 years old).

In addition to patients (24/396) in need for urgent heart valve interventions within 30 days of diagnosis, 40 patients (13.8\%) underwent either percutaneous or surgical procedures during the study period. The annual incidence of heart valve interventions was $36.47 \%$ ( $95 \%$ CI 25.17 to 47.77 ). In total, 59 heart valve interventions were undertaken in these 40 (13.8\%) patients, including $7(2.4 \%)$ percutaneous mitral

Table 2 Univariate analysis of factors associated with major cardiovascular events in 280 patients (missing data in 10/290 patients in regards to ethnicity)

\begin{tabular}{lcc}
\hline Factor & $\begin{array}{l}\text { Univariate HR } \\
(95 \% \mathrm{Cl})\end{array}$ & $\begin{array}{l}\text { Univariate } \\
\mathbf{p} \text { value }\end{array}$ \\
\hline Mild RHD & 1 & $<0.001$ \\
Moderate RHD & $8.1(2.8$ to 23.3$)$ & \\
Severe RHD & $24.9(8.8$ to 70.8$)$ & \\
ARF vs no ARF & $0.17(0.09$ to 0.30$)$ & $<0.001$ \\
Sex (male) & $0.8(0.5$ to 1.3$)$ & 0.34 \\
Melanesian* & $0.6(0.4$ to 1.1$)$ & 0.09 \\
Age group (years) & 1 & $<0.001$ \\
$\quad 5-20$ & $6.1(2.9$ to 12.41$)$ & \\
$21-40$ & $15.2(8.0$ to 28.8$)$ & \\
$>40$ & $0.13(0.07$ to 0.23$)$ & $<0.001$ \\
Ongoing secondary prophylaxis at & & \\
FU* & & \\
\hline *Analysis for 217 patients. & & \\
ARF, acute rheumatic fever; FU, follow-up; RHD, rheumatic heart disease.
\end{tabular}

Table 3 Multivariate analysis of factors associated with major cardiovascular events in 280 patients (missing data in 10/290 patients in regards to ethnicity)

\begin{tabular}{lll}
\hline Factor & Multivariate $\mathbf{H R}(95 \% \mathrm{Cl})$ & Multivariate $\mathbf{p}$ value \\
\hline Mild RHD & 1 & $<0.001$ \\
Moderate RHD & $3.36(1.10$ to 10.34$)$ & \\
Severe RHD & $10.54(3.50$ to 31.75$)$ & \\
ARF vs no ARF & $0.46(0.24$ to 0.89$)$ & 0.02 \\
Sex (male) & $0.81(0.48$ to 1.36$)$ & 0.43 \\
Melanesian & $0.66(0.37$ to 1.18$)$ & 0.16 \\
Age group (years) & & \\
5-20 & 1 & $<0.001$ \\
$21-40$ & $2.88(1.34$ to 6.22$)$ & \\
$>40$ & $5.15(2.44$ to 10.88$)$ & \\
\hline ARF, acute rheumatic fever; RHD, rheumatic heart disease. &
\end{tabular}

valvuloplasty, 5 (1.7\%) mitral valve repair, 23 (7.9\%) mitral valve replacement and 18 (6.2\%) aortic valve replacement.

Characteristics significantly associated with MACE on multivariate analysis were the severity of heart valve disease at diagnosis (moderate vs mild HR 3.36, 95\% CI 1.10 to 10.34 ; severe vs mild RHD $10.54,95 \%$ CI 3.50 to $31.75, \mathrm{p}<0.001$ ), ARF at diagnosis (HR $0.46,95 \%$ CI 0.24 to $0.89, \mathrm{p}=0.02$ ) and older age (21-40 vs $5-20$ years old, HR 2.88 , 95\% CI 1.34 to 6.22 ; $>40$ vs 5-20 years old, HR 5.15, 95\% CI 2.44 to 10.88 , $\mathrm{p}<0.01$ ) (figure 2, tables 2 and 3). After sensitivity analysis including secondary prophylaxis at the time of interview, two factors remained associated with outcomes: the severity of heart valve disease at diagnosis (moderate vs mild HR 3.22, 95\% CI 0.90 to 11.49 ; severe vs mild RHD HR 11.07 , 95\% CI 3.21 to 38.22, $\mathrm{p}<0.001$ ) and ongoing secondary prophylaxis at the time of interview (HR 0.33, 95\% CI 0.14 to $0.79, \mathrm{p}=0.013$ ) (table 4).

\section{DISCUSSION}

We present here contemporary longitudinal data of patients admitted for RHD with the longest follow-up published to date. A significant proportion of patients $(\sim 25 \%)$ are still diagnosed at the onset of complications or at a stage when heart valve interventions are urgently needed. Half our patients presented with ARF. Approximately 20\% needed heart valve intervention during the study period (median follow-up $\sim 4$ years). The annual incidence of complications and RHD-related mortality is high even in young patients who are initially admitted with uncomplicated RHD ( $59 \%$ per year). We identify factors associated with outcomes: the severity of heart valve disease at diagnosis and continuation of secondary prophylaxis. Our results suggest that early diagnosis and secondary prophylaxis is cornerstone to reducing the burden of RHD.

Our study population is young and mainly indigenous, in keeping with population-based studies in the region. ${ }^{2} 617$ The characteristics of our population are overall consistent with the two other RHD hospital-based registers published to this date. $^{10} 11$ Half our patients had ARF, as in other upper-middle-income settings. ${ }^{11}$ A history of ARF is more often reported in wealthier settings, ${ }^{11}$ suggesting the impact of healthcare services in the ability to diagnose the condition. The heart valve disease pattern is slightly different from that described in the heart of Soweto study, ${ }^{10}$ with a higher proportion of mild mitral and aortic regurgitation in our study, likely due to the 
Table 4 Sensitivity analysis of factors associated with major cardiovascular events in 217 patients (overall missing data in 73/ 290 patients in regards to secondary prophylaxis in 63 cases and ethnicity in 10 cases)

\begin{tabular}{lcc}
\hline Factor & $\begin{array}{l}\text { Multivariate HR } \\
(95 \% \mathrm{Cl})\end{array}$ & $\begin{array}{l}\text { Multivariate } \\
\mathbf{p} \text { value }\end{array}$ \\
\hline Mild RHD & 1 & $<0.001$ \\
Moderate RHD & $3.22(0.90$ to 11.49$)$ & \\
Severe RHD & $11.07(3.21$ to 38.22$)$ & 0.10 \\
ARF vs no ARF & $0.54(0.25$ to 1.14$)$ & 0.50 \\
Sex (male) & $0.82(0.47$ to 1.45$)$ & 0.84 \\
Melanesian & $1.07(0.54$ to 2.13$)$ & \\
Age group & 1 & 0.31 \\
$\quad$ 5-20 years & $1.97(0.79$ to 4.92$)$ & \\
$21-40$ years & $2.10(0.72$ to 6.10$)$ & 0.013 \\
$\quad>40$ years & $0.33(0.14$ to 0.79$)$ & \\
Ongoing & & \\
secondary & & \\
prophylaxis at FU & &
\end{tabular}

ARF, acute rheumatic fever; FU, follow-up; RHD, rheumatic heart disease.

inclusion of children and adolescents with ARF. Patients presenting with ARF were younger, with milder heart valve disease, less LV impairment and pulmonary hypertension compared with those with no ARF.

RHD is still diagnosed at an advanced stage in many cases, revealed by the onset of complications mainly in young adults. Almost one-third present with major cardiovascular complications including heart failure, stroke, non-neurological embolism or cardiovascular death. Furthermore, the incidence of heart failure was high in patients admitted with initially uncomplicated RHD ( 30\%0 per year), followed by stroke. Other complications included atrial fibrillation and haemorrhagic events. Maternal morbidity was also notable, in keeping with previous reports. ${ }^{18} 19$ Patients were at considerable risk of developing infective endocarditis, as suggested in a previous report focusing on Oceanic populations. ${ }^{20}$

When focusing on patients with uncomplicated RHD at entry, we report mortality rates of $2.4 \%$ at median 4 years follow-up. Lawrence and colleagues recently reported crude all-cause mortality rates of $3.9 \%$ at 5 years. ${ }^{2}$ Our results are, therefore, consistent with those from neighbouring Australia. However, mortality rates from New Caledonia and Australia, two highincome countries where patients have access to treatment, may not be transposable to resource-poor settings and could underestimate the global burden of the disease.

Patients with uncomplicated RHD remain at high risk of heart failure, thromboembolic events and infective endocarditis. When combining all MACEs, the annual incidence is high $(\sim 59 \%)$, considering the young age of our population. Our data may, however, help refining global burden of disease estimates in the near future.

One-fifth of our study population needed heart valve interventions during the study period. Of note, over one-third of patients had severe valve disease and heart valve interventions may have been underused, as previously described in other settings. ${ }^{21}$ Heart valve interventions are, however, not accessible in many countries where RHD remains endemic, especially in lowincome countries. $^{22-24}$

Approximately $55 \%$ of our patients were under secondary prophylaxis at follow-up. All our patients had been diagnosed with RHD $<10$ years before. ${ }^{25}$ One-fourth of our patients were, however, $\geq 40$ years old in whom secondary prophylaxis was usually stopped. The majority of children and adolescents were on secondary prophylaxis at the time of interview. However, as in other hospital-based or population-based registers, there is room for improvement in terms of adherence to guidelines. ${ }^{112526}$

We identified two factors associated with poor outcomes. The severity of valve disease at diagnosis is understandably associated with adverse events, such as heart failure ${ }^{2}$ or need of heart valve interventions. ${ }^{10}$ Continuation of secondary prophylaxis was associated with better outcomes. Patients diagnosed with RHD during an ARF attack presented better outcomes, but this was not confirmed when adjusting for secondary prophylaxis. Our results, therefore, stress the importance of early diagnosis, when heart valve disease is still mild, which bears excellent prognosis. Identifying children with ARF is an opportunity to limit the burden of disease. Our results may also suggest that screening for these mild but definite lesions could be of interest in order to avoid disease progression and future complications. ${ }^{27} 2830$

\section{Strengths and limitations}

We provide the longest follow-up data from a hospital-based RHD register including precise clinical features of the condition such as echocardiographic baseline characteristics. We used standardised criteria for RHD diagnosis ${ }^{15}$ and heart valve disease quantification. ${ }^{16}$ The study settings allowed accurate assessment of outcomes, the population being captive in a country with national mortality, overseas referrals for heart surgery and secondary prophylaxis registers. This study consistently adds to the knowledge on the burden of RHD and highlights the relatively low mortality but high morbidity of the condition in a country where medical and surgical interventions are accessible. We acknowledge, however, a series of limitations. We describe here outcomes of patients admitted to a tertiary centre with potential referral bias of most severe cases. However, many children with ARF and mild mitral regurgitation were admitted to our institution given that it is the only centre providing paediatric

\section{Key messages}

What is already known on this subject?

Rheumatic heart disease remains the leading acquired heart disease in the young worldwide, affecting patients in developing countries and among indigenous populations. Studies have mainly focused on population-based prevalence and mortality estimates. There is little knowledge on the morbidity related to rheumatic heart disease.

\section{What might this study add?}

We provide contemporary data supporting low mortality but high morbidity among indigenous populations affected by rheumatic heart disease in high-income settings. We identified two factors associated with cardiovascular outcomes: diagnosis at an early stage and continuation of secondary prophylaxis.

How might this impact on clinical practice?

This study provides further demonstration that rheumatic heart disease is a burden among young indigenous populations. Early diagnosis and secondary prophylaxis is cornerstone to limit the advent of complications and need for cardiac surgery, and should promote prevention policies. 
specialist care. We collected part of the data retrospectively, and missing data have contributed to diminishing the sample study. Diagnosis of ARF was at the discretion of the physician and did not necessarily fulfil modified Jones ${ }^{29}$ or Australasian criteria. ${ }^{25}$ However, all presented with definite RHD according to standardised WHF criteria, which implies at least one major criterion for ARF. ${ }^{15}$ Restricting our study population to patients with strict echocardiographic criteria further reduced our sample size. We focused our analysis on patients admitted with uncomplicated RHD, which underestimates the burden of the disease, but allows the identification of factors associated with the advent of adverse outcomes.

\section{CONCLUSIONS}

Newly diagnosed RHD is often revealed by complications, and outcomes are poor at follow-up especially when heart valve disease is moderate or severe and in the absence of secondary prophylaxis. Our results add to the limited data on the burden of RHD and should warrant early diagnosis when heart valve disease is still mild to introduce and continue secondary prophylaxis.

Acknowledgements We are grateful to Ms Aurélia Jewiné and Ms Nathalie Simon for their work in collecting the data. Mrs Nina Guillot provided access to the national register on secondary prophylaxis.

Contributors All authors have been involved in one or more of the following: conception and design, acquisition of data or analysis and interpretation of data, drafting the article or revising it critically for important intellectual content, final approval of the enclosed manuscript.

Funding Dr Mirabel has received funding from la Fédération Française de Cardiologie, la Fondation Lefoulon Delalande, and la Fondation pour la Recherche Médicale.

Competing interests None declared.

Patient consent Institut National de la Santé et de la Recherche Médicale waived written consent.

Ethics approval IRB Ethical Review Committee of the Institut National de la Santé et de la Recherche Médicale (French Institute of Health and Medical Research), Paris, France.

Provenance and peer review Not commissioned; externally peer reviewed.

Data sharing statement All data are available upon request from the corresponding author.

Open Access This is an Open Access article distributed in accordance with the Creative Commons Attribution Non Commercial (CC BY-NC 4.0) license, which permits others to distribute, remix, adapt, build upon this work non-commercially, and license their derivative works on different terms, provided the original work is properly cited and the use is non-commercial. See: http://creativecommons.org/ licenses/by-nc/4.0/

\section{REFERENCES}

1 Marijon E, Mirabel M, Celermajer DS, et al. Rheumatic heart disease. Lancet 2012;379:953-64

2 Lawrence JG, Carapetis JR, Griffiths K, et al. Acute rheumatic fever and rheumatic heart disease: incidence and progression in the Northern Territory of Australia, 1997 to 2010. Circulation 2013;128:492-501.

3 Steer AC, Kado J, Jenney AW, et al. Acute rheumatic fever and rheumatic heart disease in Fiji: prospective surveillance, 2005-2007. Med J Aust 2009;190:133-5.

4 Wilson N. Rheumatic heart disease in indigenous populations--New Zealand experience. Heart Lung Circ 2010;19:282-8.

5 Fauchier T, Tafflet M, Filitoga G, et al. Acute rheumatic fever: a population-based study in Wallis, a South Pacific Island. Int I Cardiol 2014;181C:30-1.

6 Mirabel M, Fauchier T, Bacquelin R, et al. Echocardiography screening to detect rheumatic heart disease: a cohort study of schoolchildren in French Pacific Islands. Int J Cardiol 2015;188:89-95.
7 Zuhlke L, Mirabel M, Marijon E. Congenital heart disease and rheumatic heart disease in Africa: recent advances and current priorities. Heart 2013;99:1554-61.

8 Lozano R, Naghavi M, Foreman K, et al. Global and regional mortality from 235 causes of death for 20 age groups in 1990 and 2010: a systematic analysis for the Global Burden of Disease Study 2010. Lancet 2012;380:2095-128.

9 Carapetis JR, McDonald M, Wilson NJ. Acute rheumatic fever. Lancet 2005:366:155-68.

10 Sliwa K, Carrington M, Mayosi BM, et al. Incidence and characteristics of newly diagnosed rheumatic heart disease in urban African adults: insights from the heart of Soweto study. Eur Heart J 2010;31:719-27.

11 Zuhlke L, Engel ME, Karthikeyan G, et al. Characteristics, complications, and gaps in evidence-based interventions in rheumatic Heart Disease: the Global Rheumatic Heart Disease Registry (the REMEDY study). Eur Heart J 2014;36:1115-22.

12 Gunther G, Asmera J, Parry E. Death from rheumatic heart disease in rural Ethiopia. Lancet 2006;367:391.

13 Bland EF, Duckett Jones T. Rheumatic fever and rheumatic heart disease; a twenty year report on 1000 patients followed since childhood. Circulation 1951;4:836-43.

14 ISEE. http://www.isee.nc/population/telecharpdf/4 page-rpnc09.pdf Secondary http:// www.isee.nc/population/telecharpdf/4 page-rpnc09.pdf (accessed 1 Jul2015).

15 Remenyi B, Wilson N, Steer A, et al. World Heart Federation criteria for echocardiographic diagnosis of rheumatic heart disease--an evidence-based guideline. Nat Rev Cardiol 2012;9:297-309.

16 Bonow RO, Carabello BA, Kanu C, et al. ACC/AHA 2006 guidelines for the management of patients with valvular heart disease: a report of the American College of Cardiology/American Heart Association Task Force on Practice Guidelines (writing committee to revise the 1998 Guidelines for the Management of Patients With Valvular Heart Disease): developed in collaboration with the Society of Cardiovascular Anesthesiologists: endorsed by the Society for Cardiovascular Angiography and Interventions and the Society of Thoracic Surgeons. Circulation 2006;114:e84-231.

17 Lennon D, Craig E. Re: Epidemiology of acute rheumatic fever in New Zealand 1996-2005 by Jaine R et al. 2008;44:564. J Paed Child Health 2009;45:764.

18 North RA, Sadler L, Stewart AW, et al. Long-term survival and valve-related complications in young women with cardiac valve replacements. Circulation 1999;99:2669-76.

19 Soma-Pillay P, MacDonald AP, Mathivha TM, et al. Cardiac disease in pregnancy: a 4-year audit at Pretoria Academic Hospital. South Afr Med I 2008;98:553-6.

20 Mirabel $M$, Andre $R$, Barsoum $P$, et al. Ethnic disparities in the incidence of infective endocarditis in the Pacific. Int J Cardiol 2015;186:43-4.

21 Mirabel $\mathrm{M}$, lung $\mathrm{B}$, Baron $\mathrm{G}$, et al. What are the characteristics of patients with severe, symptomatic, mitral regurgitation who are denied surgery? Eur Heart J 2007:28:1358-65.

22 Mirabel M, Grimaldi A, Freers J, et al. Access to cardiac surgery in sub-Saharan Africa. Lancet 2015;385:606.

23 Mirabel M, Rattanavong S, Frichitthavong K, et al. Infective endocarditis in the Lao PDR: clinical characteristics and outcomes in a developing country. Int I Cardiol 2015:180:270-3.

24 Yankah C, Fynn-Thompson F, Antunes $\mathrm{M}$, et al. Cardiac surgery capacity in sub-saharan Africa: quo vadis? Thorac Cardiovasc Surg 2014;62:393-401.

25 RHDAustralia (ARF/RHD writing group), National Heart Foundation of Australia and the Cardiac Society of Australia and New Zealand. Australian guideline for prevention, diagnosis and management of acute rheumatic fever and rheumatic heart disease (2nd edition). 2012. Secondary RHDAustralia (ARF/RHD writing group), National Heart Foundation of Australia and the Cardiac Society of Australia and New Zealand. Australian guideline for prevention, diagnosis and management of acute rheumatic fever and rheumatic heart disease (2nd edition). 2012. http:/l www.rhdaustralia.org.au/sites/default/files/guideline_0.pdf. (accessed 1 Jul 2015).

26 Remond MG, Severin $\mathrm{KL}$, Hodder $\mathrm{Y}$, et al. Variability in disease burden and management of rheumatic fever and rheumatic heart disease in two regions of tropical Australia. Int Med J 2013:43:386-93.

27 Marijon E, Ou P, Celermajer DS, et al. Prevalence of rheumatic heart disease detected by echocardiographic screening. NEJM 2007;357:470-6.

28 Marijon E, Celermajer DS, Tafflet M, et al. Rheumatic heart disease screening by echocardiography: the inadequacy of World Health Organization criteria for optimizing the diagnosis of subclinical disease. Circulation 2009;120:663-8.

29 Gewitz MH, Baltimore RS, Tani LY, et al. Revision of the Jones Criteria for the Diagnosis of Acute Rheumatic Fever in the Era of Doppler Echocardiography: A Scientific Statement From the American Heart Association. Circulation 2015;131: 1806-18.

30 Parks T, Kado J, Miller AE, et al. Rheumatic Heart Disease-Attributable Mortality at Ages 5-69 Years in Fiji: A Five-Year, National, Population-Based Record-Linkage Cohort Study. PLoS Negl Trop Dis 2015 September;9(9):e0004033. Published online 2015 September 15. doi: 10.1371/journal.pntd.0004033. 